\title{
Grapevine red blotch-associated virus Is Widespread in the United States
}

\author{
B. Krenz, J. R. Thompson, H. L. McLane, M. Fuchs, and K. L. Perry
}

First, second, third, and fifth authors: Department of Plant Pathology and Plant-Microbe Biology, 334 Plant Science, Cornell University, Ithaca, NY 14853; and fourth author: Department of Plant Pathology and Plant-Microbe Biology, Cornell University, New York State Agricultural Experiment Station, Geneva, NY 14456.

Accepted for publication 29 April 2014.

\begin{abstract}
Krenz, B., Thompson, J. R., McLane, H. L., Fuchs, M., and Perry, K. L. 2014. Grapevine red blotch-associated virus is widespread in the United States. Phytopathology 104:1232-1240.

Grapevine red blotch disease has been recognized since 2008 as affecting North American grape production. The presence of the newly described Grapevine red blotch-associated virus (GRBaV) is highly correlated with the disease. To more effectively detect and monitor the presence of the virus, a sample processing strategy and multiplex polymerase chain reaction assay were developed. A total of 42 of 113 vine samples collected in or received from seven of the United States were shown to harbor the virus, demonstrating the virus is widely distributed across North America. Phylogenetic analyses of a viral replication-associ-

ated protein (Rep) gene fragment from the 42 isolates of GRBaV demonstrated distinct clades of the virus ( 1 and 2 ), with clade 1 showing the greatest variability. The full-length genome of six virus isolates was sequenced, and phylogenetic analyses of 14 whole genomes recapitulated results seen for the Rep gene. A comparison of GRBaV genomes revealed evidence of recombination underlying some of the variation seen among GRBaV genomes within clade 1. Phylogenetic analyses of coat and replicase-associated protein sequences among single-stranded DNA viruses showed GRBaV to group within the family Geminiviridae. This grouping is distinct from members of the families Nanoviridae and Circoviridae, with limited significant affinities to both recognized genera and novel plant-infecting, gemini-like viruses.
\end{abstract}

Grapevine red blotch is an emerging disease affecting North American grape production. In 2010, a New York vineyard of Vitis vinifera 'Cabernet franc' with a severe decline described as leafroll was tested and shown to be free of recognized leafroll viruses. More detailed analyses of nucleic acids extracted from these plants not only confirmed the absence of recognized leafroll viruses, but identified the presence of a single-stranded (ss) circular DNA that was amplified using rolling circle amplification methods. Sequencing of this DNA revealed a viral genome most closely resembling that of members of the family Geminiviridae, and this virus was tentatively named Grapevine cabernet francassociated virus (GCFaV) $(16,17)$. Paralleling these studies, work began in 2008 on an emerging grapevine disease in California, since termed red blotch; this disease was typified by a leaf reddening and delayed fruit maturity in red cultivars (9). The disease was initially confused with grapevine leafroll due to the late-season symptomatology of leaf discoloration (reddening). Some red blotch symptomatic vines of cultivars Cabernet franc, Cabernet sauvignon, and Zinfandel were shown to be free of leafroll viruses. Subsequent investigations using large-scale sequencing methods revealed the presence of an ss circular DNA virus that was named Grapevine red blotch-associated virus (GRBaV) $(1,2)$. A comparison of the sequences of both GCFaV and GRBaV revealed them to be the same virus. Recognizing the significance of the California vineyard studies in helping to differentiate this as a new disease, the name GRBaV has been adopted and the original GCFaV isolate JRT456 (GenBank

Corresponding author: K. L. Perry; Email address: KLP3@ cornell.edu

http://dx.doi.org/10.1094/PHYTO-02-14-0053-R

(C) 2014 The American Phytopathological Society accession number JQ901105) and all subsequent isolates are referred to in this publication as GRBaV.

The discovery of GRBaV coincided with grower recognition of a leafroll-like disease problem in established and newly planted vineyards in both western and eastern North America $(21,27)$. The primary source of the pathogen remains uncertain. Based on the number of varieties in which $\mathrm{GRBaV}$ has been observed and the fact that the virus is transmitted by grafting $(1,16,22)$, it is likely that spread has primarily occurred through propagation material. A preliminary study has suggested a leafhopper can transmit the virus (22), but the role of a vector in the epidemiology of the disease remains to be determined. Regardless of this issue of a vector, the foundation of any control strategy will be diseasetested planting stocks.

Geminiviruses are one of the most important groups of plant viruses worldwide. These viruses primarily affect vegetable crops, with many examples of newly detected and emerging pathogens. The detection of a geminivirus in grapevine came as a surprise, as until the report of Citrus chlorotic dwarf-associated virus (CCDaV) in 2012 (18), there were no other examples of geminiviruses affecting woody crop plants. $\mathrm{CCDaV}$ is also a monopartite geminivirus with a genome organization somewhat similar to that of GRBaV. Curiously, until the discovery of the 3.64-kb genome of $\mathrm{CCDaV}$, the 3.2-kb genome of GRBaV was the largest reported size for a single component ssDNA plant virus. Though graft transmission of GRBaV has been demonstrated, virions have not been observed in infected vines.

The objectives of this study were to develop and validate tools and methods for detecting $\mathrm{GRBaV}$ and to document the genetic variability among isolates of the virus. In pursuit of these goals we have come to recognize the widespread distribution of the virus in North America and have gained a better understanding of its genomic organization. 


\section{MATERIALS AND METHODS}

Sample collection and nucleic acid extraction. Samples of grape ( $V$. vinifera) cultivars were received from cooperators or sampled in New York State. Many of the samples were selected based on leafroll-like symptoms, including those described for GRBaV (1). Total nucleic acid extracts were prepared from dormant cane scrapings or from leaves and petioles. One hundred milligrams of plant material was ground in liquid nitrogen. After adding $500 \mu \mathrm{l}$ of extraction buffer (100 mM Tris-HCl, pH 8.0; $20 \mathrm{mM}$ EDTA; $1.4 \mathrm{M} \mathrm{NaCl} ; 2 \%$ cetyltrimethylammonium bromide [CTAB]; $0.5 \mathrm{M}$ glucose, $0.2 \% \quad \beta$-mercaptoethanol, preheated to $60^{\circ} \mathrm{C}$ ), the samples were incubated at $60^{\circ} \mathrm{C}$ for $60 \mathrm{~min}$. The suspension was gently mixed for $5 \mathrm{~min}$ with one volume of chloroform/isoamylalcohol (24:1) and centrifuged at $4^{\circ} \mathrm{C}$ for $5 \mathrm{~min}$ at $13,000 \times \mathrm{g}$. To precipitate the nucleic acids, 0.8 volume of isopropanol was added to the aqueous phase, followed by $10 \mathrm{~min}$ incubation at $4^{\circ} \mathrm{C}$ and centrifugation $(13,000 \times \mathrm{g})$. Pellets were washed once with $70 \%$ ethanol, air-dried for $5 \mathrm{~min}$, and dissolved in 100 liters of water. Alternatively, CTAB extracted nucleic acids were further purified with an $\mathrm{LiCl}$ precipitation (12) and downstream modifications as previously described (29).

Enzymatic manipulations and cloning. Circular DNA was amplified from total nucleic acid extracts of grapevine by polymerase chain reaction (PCR) or rolling circle amplification (RCA) (13). RCA or PCR products were cloned and/or directly sequenced by standard methods (25). Cloning of full-length genomic DNA was achieved making use of the unique Pst restriction enzyme site in the GRBaV genome. Vectors used for cloning were pUC19 and pGEM-T vector (Promega Corp., Madison, WI).

The diagnostic primers used for amplification of a coat protein (CP) gene fragment were as follows: CPfor (5'-AGCGGAAGC ATGATTGAGACATTGACG-3'; nucleotide positions 1073 to 1099) and CPrev (5'-AACGTATGTCCACTTGCAGAAGCCGC3'; nucleotide positions 1329 to 1304). The primers used for amplification of a replication-associated protein gene fragment (Rep) were as follows: Repfor (5'-CAAGTCGTTGTAGATT GAGGACGTATTGG-3'; nucleotide positions 2567 to 2595 ) and Reprev (5'-AGCCACACCTACACGCCTTGCTCATC-3'; nucleotide positions 2884 to 2850 ). The primers used for amplification of the internal control $16 \mathrm{~S}$ rDNA fragment were as follows: 16Sfor (5'-TGCTTAACACATGCAAGTCGGA-3') and 16Srev (5'-AGCCGTTTCCAGCTGTTGTTC-3'). The thermocycling conditions were as follows: $3 \mathrm{~min}$ at $95^{\circ} \mathrm{C}, 30$ cycles of $15 \mathrm{~s}$ at $95^{\circ} \mathrm{C}$, $15 \mathrm{~s}$ at $55^{\circ} \mathrm{C}, 30 \mathrm{~s}$ at $72^{\circ} \mathrm{C}$, followed by a final $1 \mathrm{~min}$ at $72^{\circ} \mathrm{C}$. The multiplex reactions for the simultaneous detection of the $\mathrm{CP}$ gene, the Rep gene, and the control 16S rRNA fragments were carried out using a Taq $2 \times$ Mastermix (New England Biolabs, Ipswich, MA; product \#M0270) following the manufacturer's instructions and with primer molar ratios of $2: 2: 1$, respectively. The expected band size for the $\mathrm{CP}$ gene was $257 \mathrm{bp}$, for the Rep gene was $318 \mathrm{bp}$, and for the 16S rRNA was $105 \mathrm{bp}$.

Sequence and phylogenetic analyses. Sequences were assembled with the Vector NTI program (Life Technologies Inc., Grand Island, NY) and analyzed with BLAST (4). Splice sites were analyzed using the NetPlantGene server (http://www.cbs. dtu.dk/services/NetPGene/). Sequences were aligned in ClustalX (30) and the optimal nucleotide and amino acid substitution models were selected using jModeltest 2.1 .3 (11) and ProtTest (10). Phylogenetic trees were generated by three methods; neighbor-joining (CLUSTALX) (30), maximum likelihood (PAUP*) (32), and Bayesian inference (MrBayes 3.2) (24) using the selected model parameters. Recombination analyses on the full-length alignment were carried out using RDP3 software (20) and GARD (15) on the datamonkey website (http:// www.datamonkey.org/). Recombination was considered signifi- cant in RDP3 if three or more methods had $P$ values of $<0.05$, and in GARD if the KH testing $P$ value was $<0.05$. Recombination breakpoint positions were based on RDP3 predictions and considered to be supported by GARD when located within 50 nts.

\section{RESULTS}

Genomic organization of GRBaV. An understanding of the genome of GRBaV has proven important in the development of diagnostic assays that are nucleic acid based. The initial report of the sequence of an isolate of GRBaV appeared in 2012; at the time, this NY isolate (JRT456 = NY358) was designated GCFaV $(16,17)$. Five additional genomes of isolates from NY and PA have been sequenced as part of this study (Table 1, discussed below). The genome organization of all of these isolates and those published elsewhere $(1,22)$ is consistent with the genomic organization shown in Figure 1. The genome resembles that of monopartite members of the family Geminiviridae, with the orientation of the predicted open reading frames (ORFs) being bidirectional. There are three ORFs encoded in the virion-sense DNA (V1, V2, and V3) and three complementary-sense ORFs (C1, C2, and C3), as previously described $(1,16,22)$. The relative positions of three primer pairs used for the PCR-based diagnostic detection of the virus are illustrated. The two primer pairs, Repfor/Reprev and CPfor/CPrev, were developed as part of this study; the pair GVGF1/GVGR1 developed and described by Al Rwahnih et al. $(1,3)$ is shown for comparison but was not used in this study. Also observed in the genome of $\mathrm{GRBaV}$ is the conserved nonanucleotide signature motif that functions as an origin of replication, 'TAATATT|AC'; this is present in an intergenic region and observed in most all members of the family Geminiviridae (8).

BLASTN analysis (4) using the GRBaV genome (NY358, JQ901105) as a query revealed the closest related sequences, besides those of other isolates of GRBaV, to be those of Euphorbia caput-medusae latent virus (EcmLV), a newly reported geminivirus (5) with 73 to $74 \%$ identity (within a 164 nucleotide range)

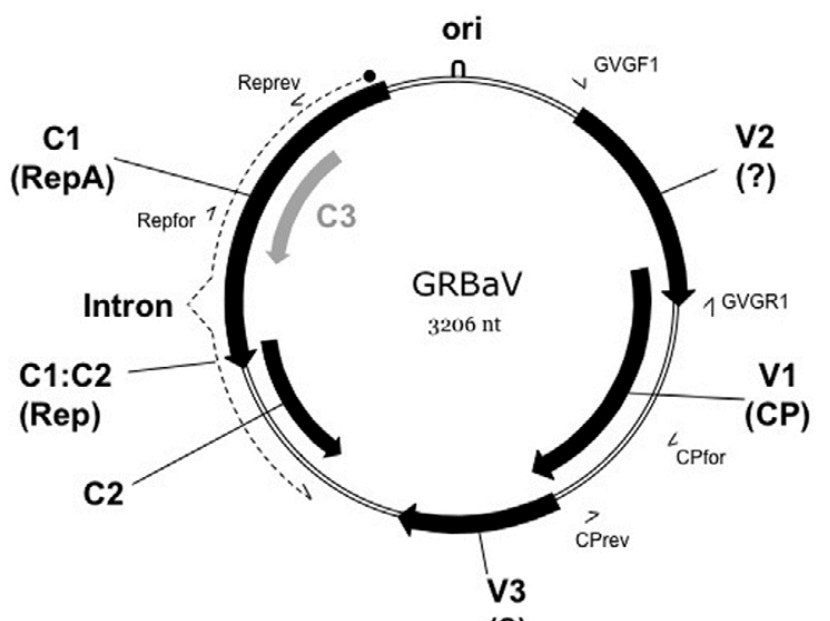

(?)

Fig. 1. Genome organization of Grapevine red blotch-associated virus (GRBaV). The circular single-stranded genome of 3,206 nucleotides is diagrammed with thick arrows indicating the open reading frames. The open reading frames and encoded proteins are as follows: V1, the coat protein $(\mathrm{CP})$; $\mathrm{V} 2$, of unknown function (noted with a question mark); V3, of unknown function; $\mathrm{C} 1$, a replication-associated protein (RepA); $\mathrm{C} 2$, the $\mathrm{c}$ terminus of the replication protein (Rep) expressed from a spliced transcript (shown as a dotted line) designated $\mathrm{C} 1: \mathrm{C} 2$; and $\mathrm{C} 3$, shaded in gray, because it is internal to $\mathrm{C} 1$ and in the same reading frame. The ori is a nonanucleotide sequence ('TAATATT|AC') that functions as an origin of replication. Also indicated in the figure with small arrows and labeled are the relative positions of primers used in the diagnostic polymerase chain reaction assays. 
and Chickpea chlorotic dwarf virus, CPCDV, genus Mastrevirus, with $88 \%$ identity (within a 52 nucleotide range). The regions of greatest sequence similarity with heterologous viruses corresponded to the C2 ORF, encoding a domain of the viral Rep protein. Whole genome comparisons showed nucleotide identities of $49 \%$ for CPCDV (KC172655) and 53\% for EcmLV (HF921459). The dicot-infecting mastrevirus CPCDV has a genome that is 634 nts smaller than GRBaV; similarly EcmLV is 529 nts smaller. $\mathrm{GRBaV}$ has a genome organization similar to both EcmLV and CPCDV, but in each of these virus species there are different numbers and placements of virion-sense ORFs.

The ORF encoding the predicted $\mathrm{CP}$ is designated V1 by convention (28). A BLASTP analysis of the encoded protein showed the strongest amino acid sequence identity (E-value 3e07) with Mesta yellow vein mosaic virus (genus Begomovirus), with 46 of 165 amino acids in common; there were multiple $(>15)$ Begomovirus species with comparable levels of identity. The functions of the V2 and V3 encoded proteins are unknown. BLASTP searches using both the amino acid sequences as queries did not reveal any non-GRBaV matches with $\mathrm{E}$ values less than 0.5 . ORFs $\mathrm{C} 1$ and $\mathrm{C} 2$ showed a subgenomic organization strikingly similar to those of mastreviruses, including a putative spliced transcript (33). Maximum amino acid identities of $33 \%$ (for $\mathrm{C} 1$ ) to $52 \%$ (for $\mathrm{C} 2$ ), with 74 and $79 \%$ coverage (BLASTX analysis) were observed with the respective ORFs of Bean yellow dwarf virus (genus Mastrevirus). The C1 ORF is homologous

TABLE 1. Isolates of Grapevine red blotch-associated virus (GRBaV) obtained from all vines testing positive for the virus ${ }^{\mathrm{a}}$

\begin{tabular}{|c|c|c|c|c|}
\hline Isolate & Cultivar & Origin & $\begin{array}{l}\text { GenBank accession number } \\
\text { for complete genome }\end{array}$ & Reference \\
\hline NY135 & Merlot & PA & KF147917 & This study \\
\hline NY137 & Cabernet franc & PA & KF147918 & This study \\
\hline NY147 & Pinot noir & NY & KF751708 & This study \\
\hline NY165 & Chardonnay & $\mathrm{CA}$ & & This study \\
\hline NY166 & Pinot noir & $\mathrm{CA}$ & & This study \\
\hline NY167 & Cabernet sauvignon & $\mathrm{CA}$ & & This study \\
\hline NY168 & Malbec & $\mathrm{CA}$ & & This study \\
\hline NY169 & Petit verdot & $\mathrm{CA}$ & & This study \\
\hline NY170 & Cabernet franc & $\mathrm{CA}$ & & This study \\
\hline NY171 & Riesling & $\mathrm{CA}$ & & This study \\
\hline NY175 & Merlot & MD & KF147916 & This study \\
\hline NY177 & Merlot & MD & & This study \\
\hline NY178 & Unknown & VA & & This study \\
\hline NY181 & Unknown & VA & & This study \\
\hline NY183 & Cabernet franc & VA & & This study \\
\hline NY184 & Cabernet franc & MD & & This study \\
\hline NY185 & Cabernet franc & MD & & This study \\
\hline NY186 & Cabernet franc & MD & & This study \\
\hline NY187 & Cabernet franc & MD & & This study \\
\hline NY188 & Cabernet franc & $\mathrm{MD}$ & & This study \\
\hline NY189 & Unknown & PA & & This study \\
\hline NY190 & Unknown & PA & & This study \\
\hline NY191 & Unknown & $\mathrm{PA}$ & & This study \\
\hline NY192 & Unknown & $\mathrm{CA}$ & & This study \\
\hline NY193 & Unknown & $\mathrm{CA}$ & & This study \\
\hline NY194 & Unknown & $\mathrm{CA}$ & & This study \\
\hline NY226 & Cabernet franc & MD & & This study \\
\hline NY271 & Cabernet franc & PA & KF147915 & This study \\
\hline NY272 & Merlot & $\mathrm{CA}$ & & This study \\
\hline NY273 & Cabernet franc & $\mathrm{CA}$ & & This study \\
\hline NY281 & Unknown & $\mathrm{CA}$ & & This study \\
\hline NY289 & Unknown & $\mathrm{CA}$ & & This study \\
\hline NY308 & Unknown & $\mathrm{CA}$ & & This study \\
\hline NY310 & Unknown & $\mathrm{CA}$ & & This study \\
\hline NY319 & Unknown & $\mathrm{CA}$ & & This study \\
\hline NY329 & Unknown & $\mathrm{CA}$ & & This study \\
\hline NY330 & Unknown & $\mathrm{CA}$ & & This study \\
\hline NY332 & Unknown & $\mathrm{CA}$ & & This study \\
\hline NY357b & Thompson seedless & Switzerland & & This study \\
\hline NY358c & Cabernet franc & NY & JQ901105 & Krenz et al. $(16,17)$ \\
\hline NY461 & Cabernet franc & NJ & & This study \\
\hline NY555 & Pinot Noir & OR & & This study \\
\hline Canada & Unknown & Canada & JX559642 & Rott and Belton (unpublished) \\
\hline CF214 & Cabernet franc & $\mathrm{CA}$ & KC896623 & Al Rwahnih et al. $(2,3)$ \\
\hline CS337 & Cabernet franc & $\mathrm{CA}$ & KC896624 & Al Rwahnih et al. $(2,3)$ \\
\hline $\mathrm{Z} 1 \mathrm{~A}$ & Zinfandel & $\mathrm{CA}$ & KC896625 & Al Rwahnih et al. $(2,3)$ \\
\hline GRLaV-WA1 & Unknown & WA & KC427993 & Poojari et al. (22) \\
\hline GRLaV-WA2 & Unknown & WA & KC427994 & Poojari et al. (22) \\
\hline GRLaV-WA-MR & Merlot & WA & KC427995 & Poojari et al. (22) \\
\hline GRLaV-WA-CF & Cabernet franc & WA & KC427996 & Poojari et al. (22) \\
\hline
\end{tabular}

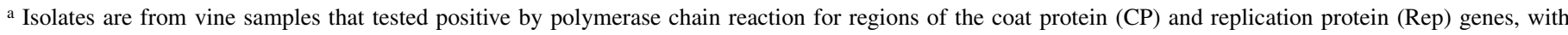
confirmation by sequencing of the amplified Rep fragments. GenBank accession numbers are indicated for GRBaV isolates that were sequenced in their entirety. The cultivars of grapevine are indicated where known.

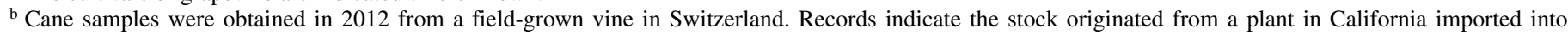
Switzerland in 1985.

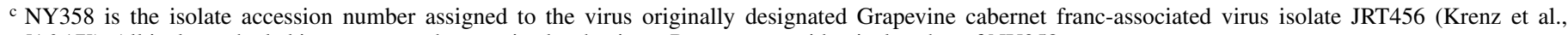
$[16,17])$. All isolates shaded in gray were characterized as having a Rep sequence identical to that of NY358. 
with the gene encoding the replication-associated protein A (RepA) of Maize streak virus (MSV) and other members of the genus Mastrevirus. The C2 ORF is likely expressed as the $3^{\prime}$ end of a spliced transcript with $5^{\prime}$ sequences encoded to yield the Rep protein (6). The GRBaV genome was analyzed using splicing prediction programs for putative splicing donor and acceptor sites $(14,23)$. A proposed donor site based on the work of Schalk et al. (26) was confirmed by the prediction programs, but no acceptor site was clearly identified. Nevertheless, we are able to predict a $163 \mathrm{nt}$ intron (positions 2288 to 2450 in the reference genome of NY358, JQ901105) based on previous studies of mastrevirus replication and splicing (26), with a 264 aa RepA (encoded by the reverse complement of nucleotides 3044 to 2250) and a 327 aa Rep protein translated from a spliced transcript (the reverse complement of nucleotides 3044 to 2451,2287 to 1898). ORF C3 is internal to $\mathrm{C} 1$ (shaded in Fig. 1), and because it is in the same reading frame as $\mathrm{C} 1$, it is not thought to be independently translated.

Sample processing strategy and multiplex PCR. A primary objective in this study was to develop and validate tools and processes for detecting GRBaV. Following the initial discovery of the virus and the description of its genome, primers were designed for use in a PCR-based screen for the virus. These primers targeted regions in the $\mathrm{CP}(\mathrm{V} 1)$ and RepA $(\mathrm{C} 1)$ genes of the virus (Fig. 1). Recognizing that sequence divergence among virus isolates might result in false negatives in PCR assays, our strategy has been to test for two separate encoded gene sequences. In our sample processing scheme (Fig. 2), plant nucleic acid samples were initially tested by simplex or multiplex PCR using primers specific to the GRBaV sequences (Fig. 3). Samples testing negative for GRBaV, but positive for the internal PCR control, were subsequently subjected to the sequence-independent RCA assay

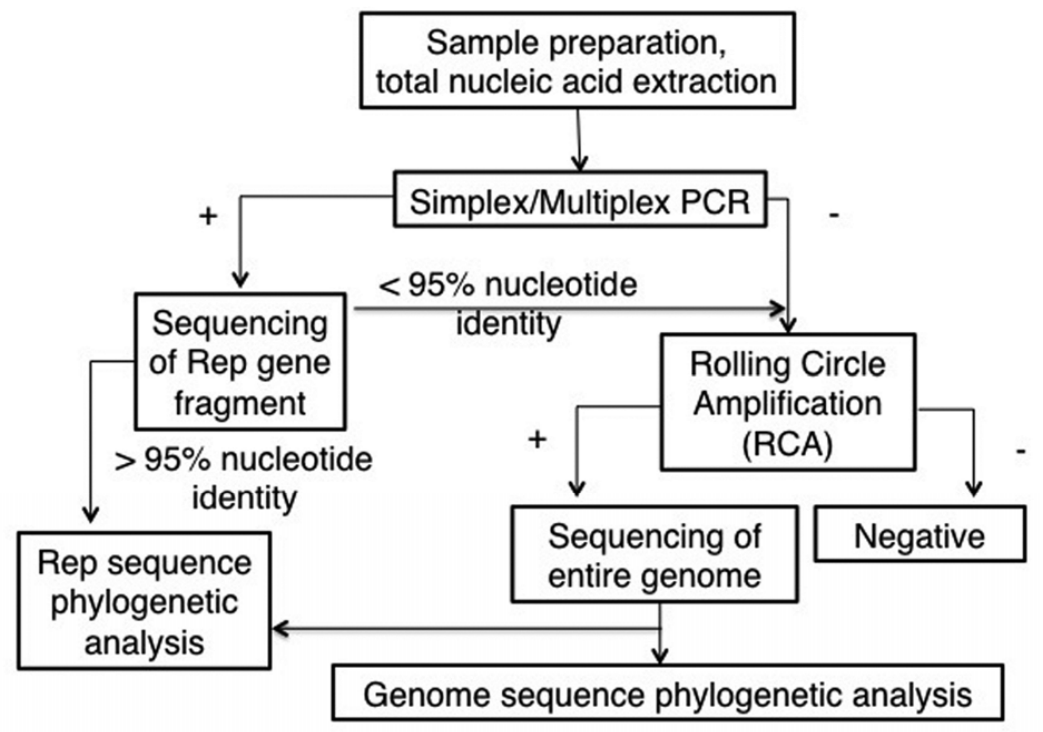

Fig. 2. Strategy for the processing of samples to test for Grapevine red blotch-associated virus (GRBaV). The flow path for handling samples is diagramed from the initial sample preparation of total nucleic acids to a determination of GRBaV infection status with sequence information from the genome.

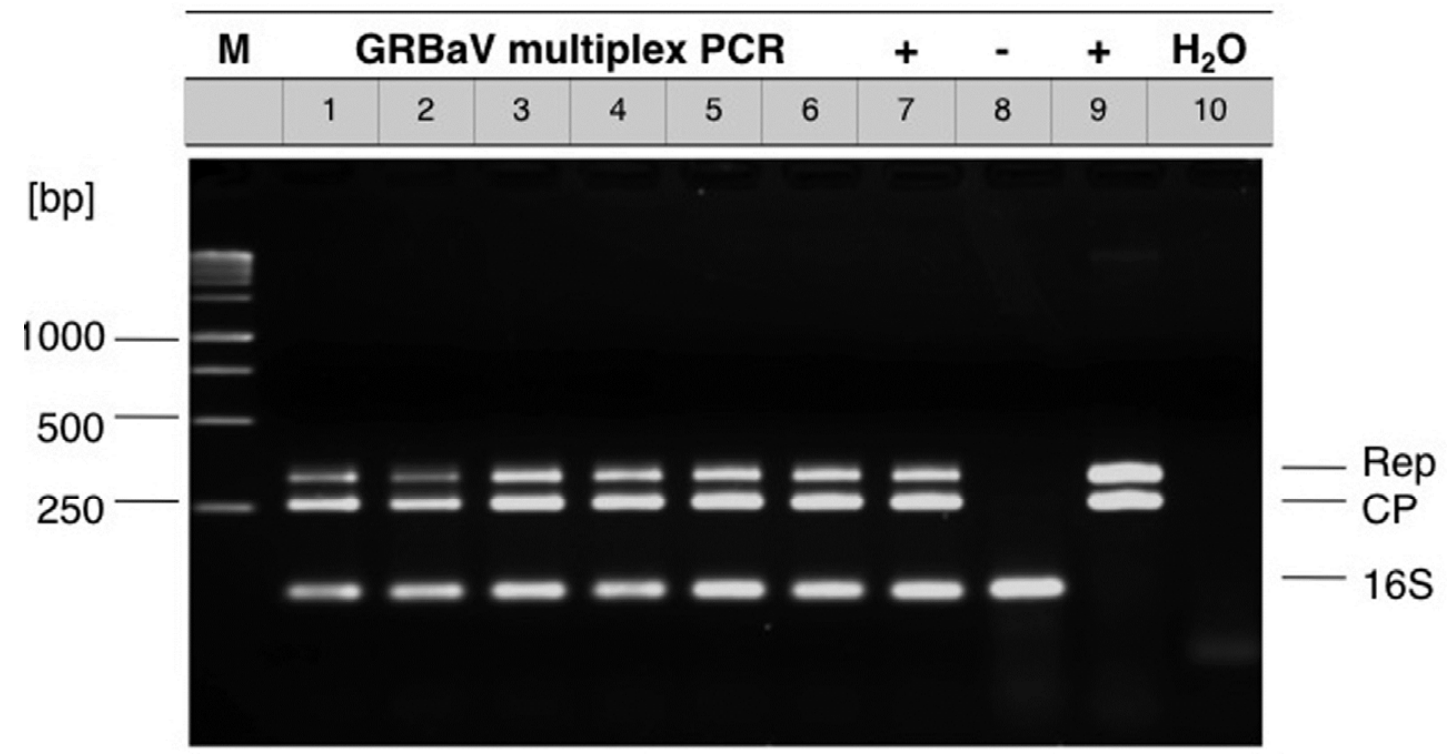

Fig. 3. Detection of Grapevine red blotch-associated virus (GRBaV) by multiplex polymerase chain reaction (PCR). PCR products are shown in an ethidium bromide-stained agarose gel following electrophoresis. The primers employed in the PCR were specific to the viral replicase (Rep) and coat protein (CP) genes, and to a plant 16S ribosomal RNA gene. The positions of DNA molecular weight markers and PCR products are indicated on the left and right of the figure, respectively. Lane 0 , molecular weight markers; lanes 1 to 6 , infected vine samples; lane 7 , positive infected plant control; lane 8 , uninfected negative plant control; lane 9, cloned GRBaV genomic DNA; and lane 10, a water control. 
that will amplify circular DNA templates. Since RCA products can also be of host origin, any amplified RCA product needs to be sequenced in order to confirm a detection of GRBaV. Plants testing negative in both assays were assumed to be negative for GRBaV. For all GRBaV positive samples, the amplified Rep gene fragments were sequenced. Any sample showing less than $95 \%$ sequence identity with the original GRBaV-JRT456 RepA gene fragment represented a potential genetic variant and was subject to RCA amplification and whole genome sequencing. This overall approach, diagrammed in Figure 2, was adopted for the handling and testing of grapevine samples in this study. It provided a uniform strategy to allow us to assess the variability the genome among isolates and evaluate the reliability of primers for diagnostic use and avoiding false negatives. Thus far, we have not observed any isolates for which either of the diagnostic primer pairs designed in this study failed to amplify a corresponding product.

GRBaV is observed in vines from seven states. One hundred thirteen vine samples were collected in or received from eight of the United States (CA, FL, MD, NJ, NY, OR, PA, and VA), with most from plants exhibiting symptoms typical of leafroll or GRBaV $(1,2,16,17)$. Forty-two of these samples originating from seven states tested positive for GRBaV (Table 1). Half of the
GRBaV-infected field collections were from vines with Grapevine leafroll-associated virus-like symptoms (leaf cupping, leaf reddening in the case of red varieties or leaf chlorosis in white varieties, especially as occurring toward the end of the season). The remainder of the infected samples was received from collaborators and industry representatives, without information on plant appearance. The virus was identified in nine different grape cultivars. Of the $26 \mathrm{GRBaV}$ positive vines of known cultivar identity, all but three were from red grape varieties, consistent with the discovery and initial reports of the virus from red grape varieties with altered foliar pigments. One of the white variety exceptions was NY357, a plant of the cultivar Thompson Seedless that originated as cane material from a field-grown vine in Switzerland and was propagated in a quarantine greenhouse at Cornell University; this was the only material in this study that originated from outside of North America.

Sequencing of fragments from the Rep gene reveals sequence divergence among isolates. Sequences of the Rep gene and protein are some of the most conserved in the virus genome, as seen in the initial BLASTN analysis described above. In order to obtain an indicator of sequence diversity among isolates of GRBaV, we sequenced a 242 nt region within a 381-bp DNA
A

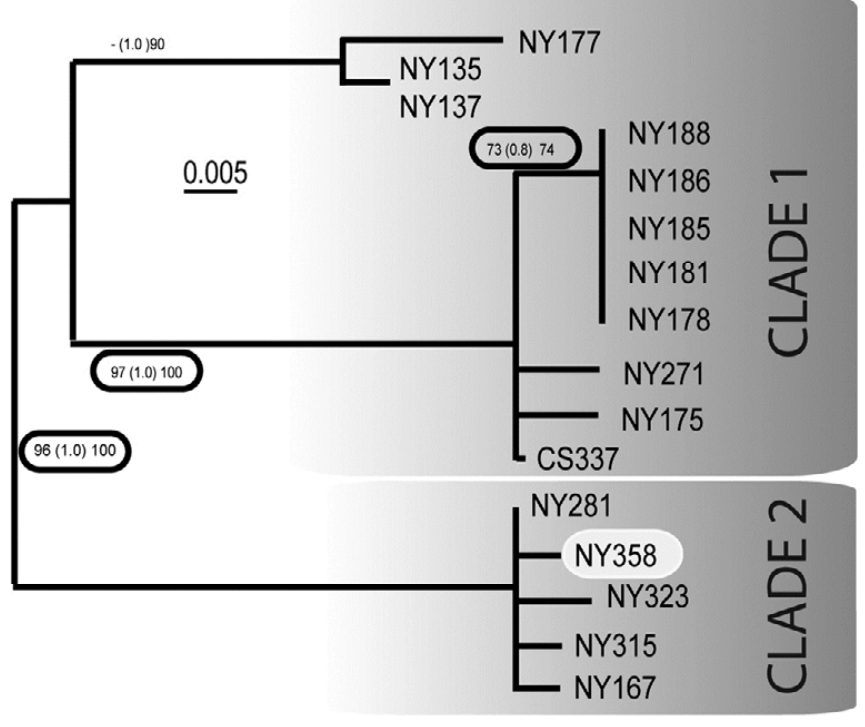

$\mathrm{B}$

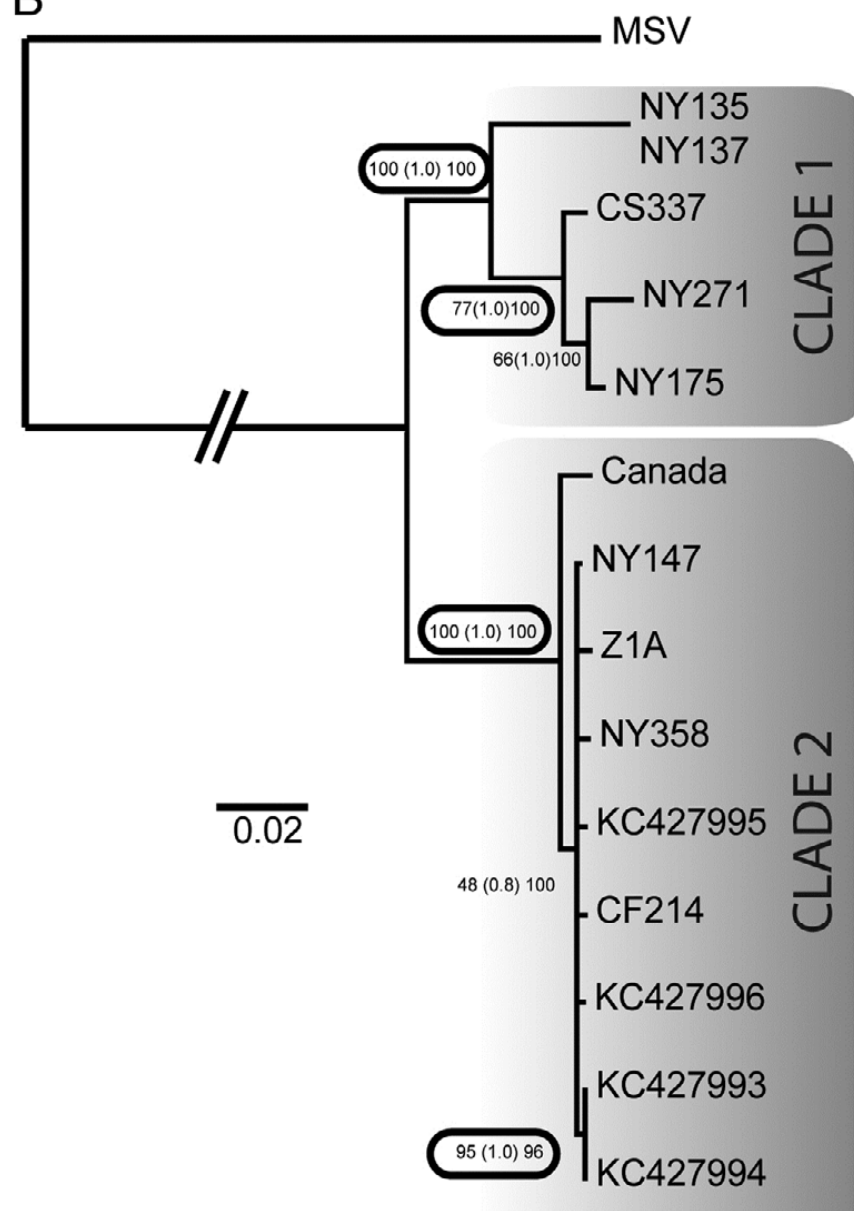

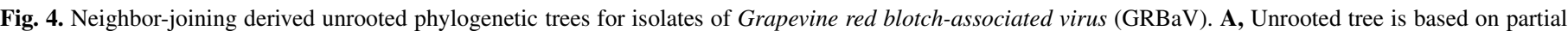

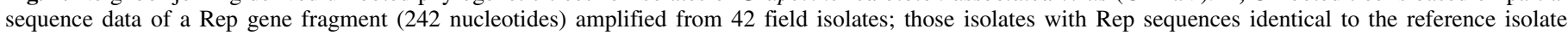

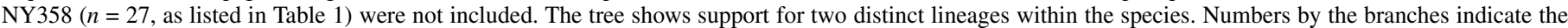

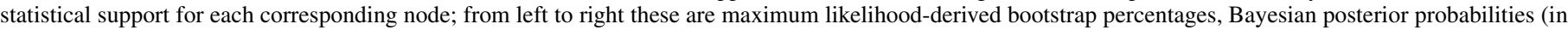

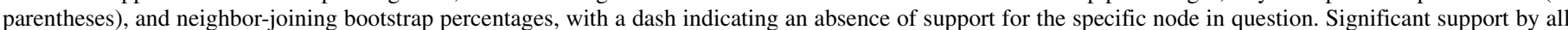

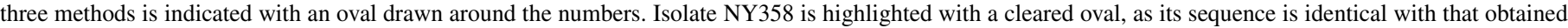

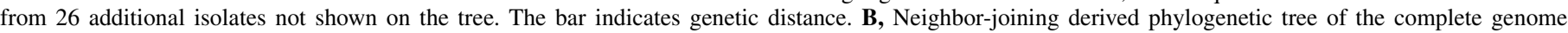

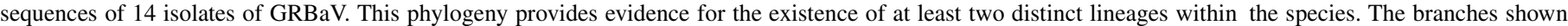

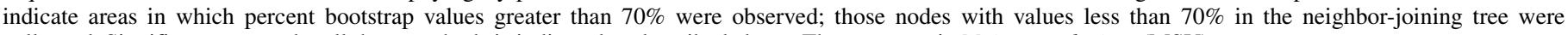
collapsed. Significant support by all three methods is indicated as described above. The outgroup is Maize streak virus (MSV). 
fragment amplified with primers Repfor and Reprev. The Rep sequences of the $42 \mathrm{GRBaV}$ isolates listed in Table 1 were aligned and a neighbor-joining derived, unrooted phylogenetic tree was generated (Fig. 4A). A grouping of the isolates into two major clades was statistically supported using three different methods (bootstrap values $[>70 \%]$ in maximum likelihood and neighborjoining values, and posterior probabilities [>0.9] in Bayesian analysis). A similar grouping of $\mathrm{GRBaV}$ isolates was observed using full-length genomes for comparison (Fig. 4B; discussed below). The majority of the isolates (32 of 42) were in clade 2, and 26 of these showed $100 \%$ nucleotide identity with the Rep gene from isolate NY358 (Table 1).

Phylogenetic tree obtained with Rep sequences differs from that with $\mathrm{CP}$ sequences. In order to estimate phylogenetic relatedness of GRBaV with other ssDNA viruses, the sequences of the Rep and CP gene products were compared with the corresponding gene products of other ssDNA viruses including members of the families Geminiviridae, Nanoviridae, and Circoviridae, and other newly identified viruses. For these comparisons, the complete gene sequences from two GRBaV isolates were employed, NY271 (representing clade 1) and NY358 (representing clade 2). With regard to Rep gene sequences, the GRBaV isolates group significantly outside of the begomo-, topocu-, curto-, and becurtovirus clades, grouping polyphyletically with the mastreviruses and Sclerotinia sclerotiorum hypovirulenceassociated DNA virus (SSHaDV) (Fig. 5A). By contrast, when comparing $\mathrm{CP}$ gene sequences, GRBaV is most closely related to members of the genus Begomovirus, with significant support from two out of three methods (neighbor-joining and Bayesian inference, Fig. 5B).

A comparison of GRBaV genomes indicates recombination among GRBaV isolates. In order to measure genomic sequence diversity among isolates of $\mathrm{GRBaV}$, we sequenced and analyzed the genomes of six isolates: NY135, NY137, NY147, NY175, NY271, and the previously published isolate NY358 (=JRT456). These sequences were compared with the published genome sequences of eight additional isolates (listed in Table 1). The majority of genomes (9 of 14) showed $98.8 \%$ or greater sequence
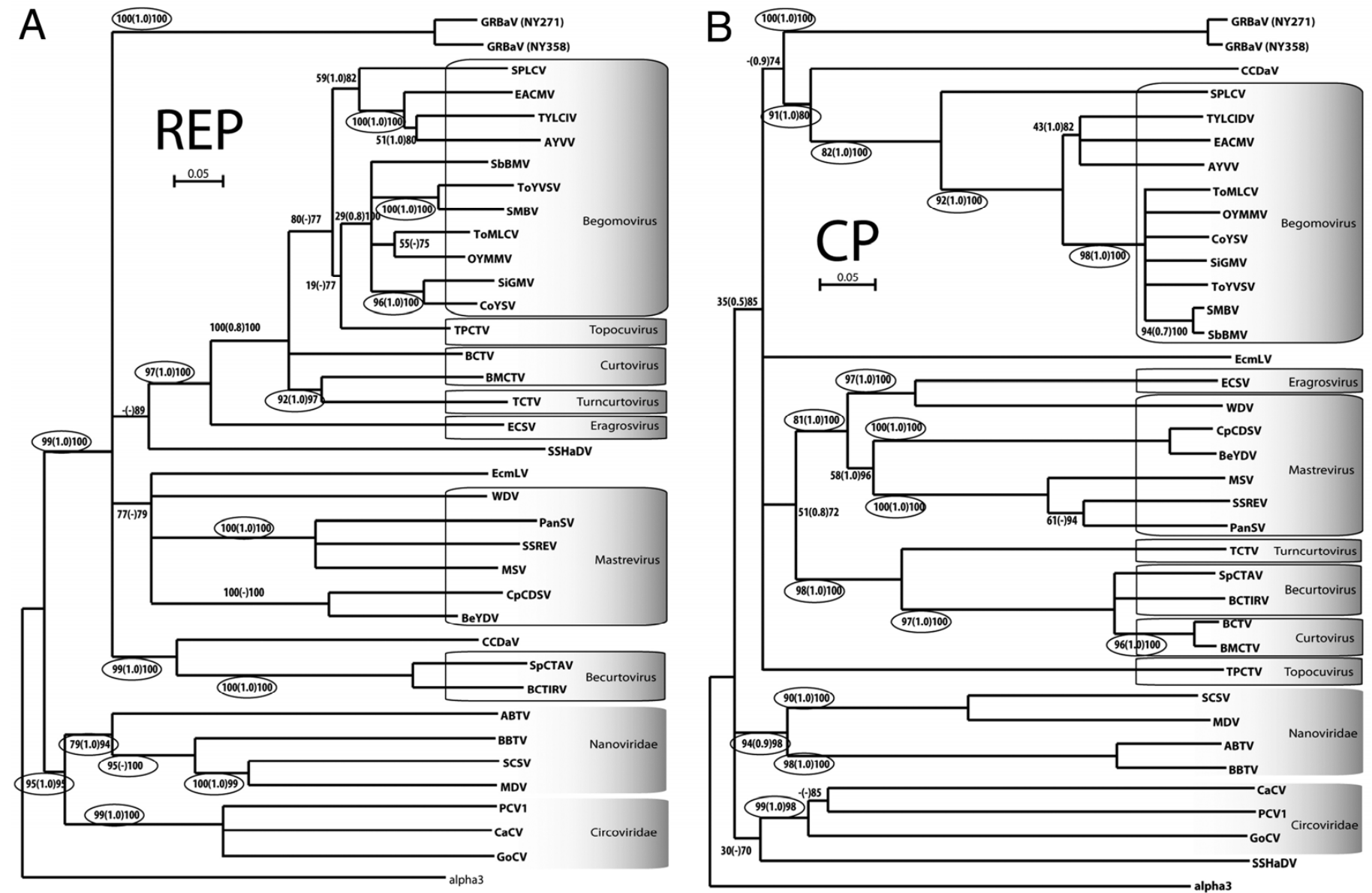

Fig. 5. Maximum likelihood rooted trees of the A, Rep protein and $\mathbf{B}$, coat protein $(\mathrm{CP})$ of Grapevine red blotch-associated virus (GRBaV) and other singlestranded DNA viruses. Included are selected members of the families Geminiviridae (genera Becurtovirus, Begomovirus, Curtovirus, Eragrovirus, Mastrevirus, Topocuvirus, and Turncurtovirus), Circoviridae, Nanoviridae, and unclassified viruses of plants and fungi. The outgroup is alpha3. The acronyms, full species names, and genome sequence accession numbers are as follows: ABTV, Abaca bunchy top virus, NC_010319, NC_010316; AYVV, Ageratum yellow vein virus, AJ564744; BBTV, Banana bunchy top virus, EU531473, EF687856; BeYDV, Bean yellow dwarf virus, NC_003493; BCTIRV, Beet curly top Iran virus, JQ707938; BCTV, Beet curly top virus, AF379637; BMCTV, Beet mild curly top virus, HQ214016; CaCV, Canary circovirus, AJ301633; CpCDV, Chickpea chlorotic dwarf virus, NC_010289; CCDaV, Citrus chlorotic dwarf associated virus, NC_018151; CoYSV, Corchorus yellow spot virus, NC_008492; EACMKV, East African cassava mosaic Kenya virus, AJ717575; Enterobacteria phage alpha3, NC_001330; ECSV, Eragrostis curvula streak virus, FJ665632; EcmLV, Euphorbia caput-medusae latent virus, HF921477; GoCV, Goose circovirus, AF536941; MSV, Maize streak virus, HQ693290; MDV, Milk vetch dwarf virus, NC_003638,AB009046; OYMMV, Okra yellow mosaic Mexico virus, HQ020409; PanSV, Panicum streak virus, GQ415395; PCV1, Porcine circovirus, AY184287; SSHaDV-1, Sclerotinia sclerotiorum hypovirulence associated DNA virus 1, NC_013116; SiGMV, Sida golden mosaic Braco virus, HQ009521; SMBV, Solanum mosaic Bolivia virus, HM585435; SbBMV, Soybean blistering mosaic virus, EF016486; SpSCTAV, Spinach severe curly top virus, HQ443515; SCSV, Subterranean clover stunt virus, NC_003818, NC_003817; SSREV, Sugarcane streak Reunion virus, NC_004755; SPLCV, Sweet potato leaf curl Uganda virus, NC_014968; ToMLCV, Tomato mottle leaf curl Zulia virus, NC_015122; TPCTV, Tomato pseudo-curly top virus, NC_003825; TYLCIDV, Tomato yellow leaf curl Indonesia virus, NC_008267; ToYVSV, Tomato yellow vein streak virus, EF459696; TCTV, Turnip curly top virus, GU456685; and WDV, Wheat dwarf virus, AM296019. 
A
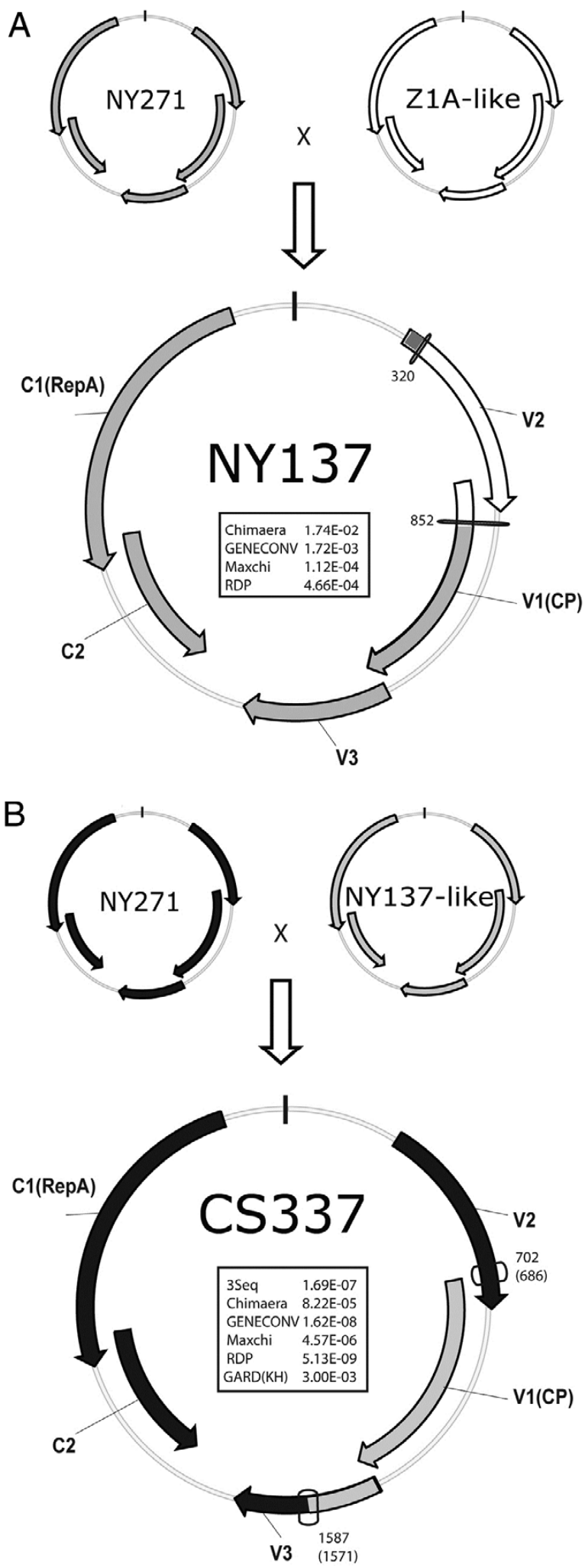

Fig. 6. Evidence of recombination in Grapevine red blotch-associated virus $(\mathrm{GRBaV})$. A, A recombination event at nucleotide positions 320 and 852 (reference genome KF147918) is shown, as detected by 4 of 12 RDP3 statistical methods. The recombination event illustrated is between the clade 1 isolate NY271 and a clade 2 parental isolate (Z1A-like) to generate NY137. B, Recombination breakpoints are shown at the $3^{\prime}$ terminus of the V2 open reading frame and within the V3 open reading frame. These sites are marked with ovals that cover the indicated nucleotide positions of the breakpoints (reference genome KF147918) as predicted by 5 of 12 RDP3 statistical methods and the algorithm GARD (numbers in parentheses). The algorithms and statistical significance values $(P<0.05)$ for the detection of recombination are indicated in the boxes within the progeny genomes. identity, all among isolates in clade 2 (Fig. 4B) as represented by isolate NY358. Overall, the five isolates grouping into clade 1 showed the greatest sequence variability both between and within clades, at 91.5 and $94.8 \%$, respectively. Curiously, although two of the clade 1 isolates had an identical genome sequence (NY135 and NY137), these were isolated from two different cultivars and represented the aforementioned most dissimilar sequence from the other isolates.

Given that recombination appears to be common among members of the family Geminiviridae (19), the publicly available full-length GRBaV genomes were analyzed for indications of recombination using a suite of statistical models. Consistent with our earlier analysis of CP and Rep gene sequences (Fig. 5) and the sequence heterogeneity observed among clade 1 isolates, four of the nine RDP3 algorithms provide evidence $(P<0.0174)$ that the clade 1 isolate NY137 arose via recombination at positions 320 and 852 (reference genome KF147918; Fig. 6A). These positions correspond to $5^{\prime}$ and $3^{\prime}$ termini of the $\mathrm{V} 2$ gene, and NY137 is predicted to be a recombinant wherein a V2 gene was introduced into NY271 from a clade 2, Z1A-like isolate. A greater degree of statistical support was observed for a second recombination event shown in Figure 6B. The illustrated recombination signals were detected using 5 of the 12 RDP3 programs as well as the algorithm GARD. The breakpoints span windows of $16 \mathrm{nt}$ and map to the 3' end of the V2 gene (positions 686 to 702, reference genome KF147916), $5^{\prime}$ of the V1 gene, and to within the V3 gene, downstream of the $3^{\prime}$ end of the V1 gene. NY175 (or CS337) is predicted to be a recombinant wherein a V1 gene and part of the V3 gene are introduced into NY271 from a clade 1, NY137-like isolate.

\section{DISCUSSION}

A robust strategy for the detection of GRBaV has been designed and validated in the testing of grapevine samples from vineyards across the United States. The detection of this virus in samples from seven states, plus previous reports of the virus in California (1), Washington (22), Oregon (GenBank accession KF137562), Georgia (7), and Canada (GenBank accession JX559642) indicate that this pathogen is widespread in North America. All of the hosts in which GRBaV was detected were cultivars of $V$. vinifera. Of the subset of positive samples in this study wherein the cultivar was recorded, half (13 of 26) were of a single cultivar, Cabernet franc. Although some of the vines sampled without detection of the virus were cultivars of $V$. rotundifolia and interspecific Vitis species, no inferences can be made about the prevalence of GRBaV among cultivars or species, because the sampling was not random. The overrepresentation of GRBaV in Cabernet Franc is presumably due to biased sampling, as this cultivar can be highly symptomatic $(1,16)$. One GRBaV positive sample originated from a field grown vine in Europe, though this alone is not indicative of any wider presence, as records indicate the sample from Switzerland originated as an accession from California imported in 1985. Nonetheless, given that grapevine germplasm is traded internationally, it is expected that the virus will be detected worldwide. Operationally, there should be no impediments to the detection of GRBaV with the currently available methods. It should be noted that any RCA products need to be critically examined, as host mitochondrial DNA amplicons are observed (data not shown) and will confuse interpretation. We have successfully amplified GRBaV DNAs from both new growth in spring and from fruit and older leaf tissues in fall, though difficulty in obtaining high quality DNA from the older leaf tissues can compromise detection.

Grapevine red blotch was first recognized and tracked as a disease in California in 2008 (2). Prior to this time, the virus was presumably present, but the associated symptoms overlapped with and were not distinguished from those caused by the leafroll 
viruses. While a description of a causal relationship between the virus and disease has not yet been published, the correlation between the detection of the viral DNA and the presence of symptoms in red wine varieties in California has been very strong (3). Proving a causal role for a virus in disease can be challenging, especially in perennial crops. GRBaV has been transmitted into grapevine through the use of a cloned DNA intermediate delivered by an Agrobacterium vector (unpublished data), and this experimental system will allow an assessment of associated symptoms. This should be especially revealing for white cultivars, in which the virus has been detected but an associated symptomatology has not been consistently described.

The full-length genomes of six isolates of GRBaV were sequenced and the genome organization in these and eight additional published genomes is conserved. Based on analyses of the Rep gene, this virus is most closely related to members of the family Geminiviridae, genus Mastrevirus, although this relationship is not definitive in that if we consider all three tree methods, $\mathrm{GRBaV}$ groups within the family Geminiviridae, but outside all recognized genera except Mastrevirus, SSHaDV, Citrus chlorotic dwarf virus (CCDV), and EcmLV. The overall genome organization is similar to mastreviruses and additional newly described geminiviruses such as CCDV. GRBaV and CCDV are the only reported geminiviruses of woody hosts (18). The major organizational differences correspond to other virus-sense ORFs in addition to the $\mathrm{V} 1$ encoding the $\mathrm{CP}$. In the case of GRBaV, novel proteins are encoded by the ORFs V2 and V3. BLASTP searches (4) using both the V2 and V3 sequences as queries did not reveal any non-GRBaV matches with E values less than 0.5. Similarly, a PSI-BLAST analysis of all nonredundant protein sequences with V2 and V3 sequences did not show any expected matches. If the database being searched was restricted to viral sequences (taxid: 10239), following PSI-BLAST iterations, one of the matches with V2 was to a hypothetical protein (NP_066182) of the geminivirus Horseradish curly top virus (HrCTV) with 22 identical of 99 amino acids, including the sequence RHCLFTYKCE (with conserved amino acids in bold). Based on analogy with other monopartite geminiviruses wherein functional analyses have been performed, either or both of these genes might encode candidate proteins involved in virus movement.

There are two major phylogenetic clades of GRBaV, with sequence differences of up to $8.5 \%$ of the genome. Approximately $75 \%(32 / 42)$ of the isolates observed in this study were allied with clade 2 isolates. The clade 1 isolates were fewer and more divergent in sequence. In phylogenetic analyses of the Rep and CP genes, maximum likelihood, neighbor-joining, and Bayesian posterior probabilities all place GRBaV in a separate branch from members of the seven currently recognized genera in the family Geminiviridae. GRBaV also separates as a distinct branch relative to the woody host geminivirus CCDV and a mastrevirus-like virus of a fungus (SSHaDV) (Fig. 6). Given the limited sequence relatedness to any other ssDNA virus, GRBaV will likely be assigned to a new genus within the family Geminiviridae. In a recent taxonomic revision of this family, three additional genera were established and the need for a new genus to accommodate GRBaV was noted (31). GRBaV is an emerging pathogen having been first recognized in grapevines during the past 3 years. Although the virus has presumably been present in planting material for decades, its presence went undetected because the symptomatology overlaps with that associated with the leafroll viruses, and any disease due to GRBaV would have been thought to be due to leafroll viruses. If isolate NY357 was present in California in 1985, this would suggest that the virus was circulating in the United States for at least 29 years, a figure not unlikely given the present distribution of the virus. With currently available diagnostic methods such as those described in this report, the global distribution of this intriguing virus should soon be made clear.

\section{ACKNOWLEDGMENTS}

This work was supported in part by funding from the U.S. Department of Agriculture Animal Plant Health Inspection Service as part of the National Clean Plant Network, by Agriculture and Food Research Initiative Competitive Grant no. 2009-55605-05184 from the USDA National Institute of Food and Agriculture, by the American Vineyard Foundation, the New York Wine and Grape Foundation, and the New York Farm Viability Institute. We thank L. T. Morton, V. Tsolova, A. Wei of AgriAnalysis LLC, J. Monis of Eurofins STA Laboratories, and A.-L. Fabritius of AL\&L Crop Solutions for their generous assistance, with apologies to anyone whose name may have been overlooked.

\section{LITERATURE CITED}

1. Al Rwahnih, M., Ashita, D., Anderson, M., Rowhani, A., Uyemoto, J. K., and Sudarshana, M. R. 2013. Association of a DNA virus with grapevines affected by red blotch disease in California. Phytopathology 103:10691076.

2. Al Rwahnih, M., Dave, A., Anderson, M., Uyemoto, J. K., and Sudarshana, M. R. 2012. Association of a circular DNA virus in grapevines affected by red blotch disease in California. Proc. 17th Congress of the International Council for the Study of Virus and VirusLike Diseases of the Grapevine (ICVG), Davis, CA.

3. Al Rwahnih, M., Dave, A., Anderson, M. M., Rowhani, A., Uyemoto, J. K., and Sudarshana, M. R. 2013. Association of a DNA virus with grapevines affected by red blotch disease in northern California. (Abstr.) Phytopathology 103(suppl.):S2.4.

4. Altschul, S. F., Madden, T. L., Schaffer, A. A., Zhang, J. H., Zhang, Z., Miller, W., and Lipman, D. J. 1997. Gapped BLAST and PSI-BLAST: A new generation of protein database search programs. Nucleic Acids Res. 25:3389-3402.

5. Bernardo, P., Golden, M., Akram, M., Naimuddin, Nadarajan, N., Fernandez, E., Granier, M., Rebelo, A. G., Peterschmitt, M., Martin, D. P., and Roumagnac, P. 2013. Identification and characterisation of a highly divergent geminivirus: Evolutionary and taxonomic implications. Virus Res. 177:35-45.

6. Boulton, M. I. 2002. Functions and interactions of mastrevirus gene products. Physiol. Mol. Plant Pathol. 60:243-255.

7. Brannen, P. M., Deom, C. M., Westmoreland, M., Collins, P., Alabi, O., and Rayapati, N. 2013. Prevalence of grapevine (Vitis vinifera) viruses in Georgia. (Abstr.) Phytopathology 103(suppl.):S2.20.

8. Brown, J. K., Fauquet, C. M., Briddon, R. W., Zerbini, R. W., Moriones, E., and Navas-Castillo, J. 2012. Geminiviridae. In: Virus Taxonomy. A. M. Q. King, ed. Elsevier/Academic Press, Amsterdam.

9. Calvi, B. L. 2011. Effects of red-leaf disease on Cabernet Sauvignon at the Oakville experimental vineyard and mitigation by harvest delay and crop adjustment. M.S., University of California, Davis.

10. Darriba, D., Taboada, G. L., Doallo, R., and Posada, D. 2011. ProtTest 3: Fast selection of best-fit models of protein evolution. Bioinformatics 27:1164-1165.

11. Darriba, D., Taboada, G. L., Doallo, R., and Posada, D. 2012. jModelTest 2: More models, new heuristics and parallel computing. Nat. Methods 9:772-772.

12. Gambino, G., Perrone, I., and Gribaudo, I. 2008. A rapid and effective method for RNA extraction from different tissues of grapevine and other woody plants. Phytochem. Anal. 19:520-525.

13. Haible, D., Kober, S., and Jeske, H. 2006. Rolling circle amplification revolutionizes diagnosis and genomics of geminiviruses. J. Virol. Methods 135:9-16.

14. Hebsgaard, S. M., Korning, P. G., Tolstrup, N., Engelbrecht, J., Rouze, P., and Brunak, S. 1996. Splice site prediction in Arabidopsis thaliana DNA by combining local and global sequence information. Nucleic Acids Res. 24:3439-3452.

15. Kosakovsky Pond, S. L., Posada, D., Gravenor, M. B., Woelk, C. H., and Frost, S. D. W. 2006. GARD: A genetic algorithm for recombination detection. Bioinformatics 22:3096-3098.

16. Krenz, B., Thompson, J., Fuchs, M., and Perry, K. L. 2012. Complete genome sequence of a new circular DNA virus from grapevine. J. Virol. 86:7715.

17. Krenz, B., Thompson, J. R., Fuchs, M., and Perry, K. L. 2012. Complete genome sequence of a new circular DNA virus from grapevine. Proc. 17th Congress of the International Council for the Study of Virus and VirusLike Diseases of the Grapevine (ICVG), Davis, CA.

18. Loconsole, G., Saldarelli, P., Doddapaneni, H., Savino, V., Martelli, G. P., and Saponari, M. 2012. Identification of a single-stranded DNA virus associated with citrus chlorotic dwarf disease, a new member in the family Geminiviridae. Virology 432:162-172. 
19. Martin, D. P., Lefeuvre, P., Varsani, A., Hoareau, M., Semegni, J.-Y., Dijoux, B., Vincent, C., Reynaud, B., and Lett, J.-M. 2011. Complex recombination patterns arising during geminivirus coinfections preserve and demarcate biologically important intra-genome interaction networks. PLoS Pathogens 7.

20. Martin, D. P., Lemey, P., Lott, M., Moulton, V., Posada, D., and Lefeuvre, P. 2010. RDP3: A flexible and fast computer program for analyzing recombination. Bioinformatics 26:2462-2463.

21. Morton, L. 2013. On the trail of red blotch virus: View from the East. Wine Business Monthly, March:132-139.

22. Poojari, S., Alabi, O. J., Fofanov, V. Y., and Naidu, R. A. 2013. A leafhopper-transmissible DNA virus with novel evolutionary lineage in the family geminiviridae implicated in grapevine redleaf disease by nextgeneration sequencing. Plos One 8:e64194.

23. Reese, M. G., Eeckman, F. H., Kulp, D., and Haussler, D. 1997. Improved splice site detection in Genie. J. Comput. Biol. 4:311-323.

24. Ronquist, F., and Huelsenbeck, J. P. 2003. MrBayes 3: Bayesian phylogenetic inference under mixed models. Bioinformatics 19:1572-1574.

25. Sambrook, J., and Russell, D. W. 2001. Molecular Cloning: A Laboratory Manual. 3rd ed. Cold Spring Harbor Laboratory, Cold Spring Harbor, NY.

26. Schalk, H. J., Matzeit, V., Schiller, B., Schell, J., and Gronenborn, B. 1989. Wheat dwarf virus, a geminivirus of graminaceous plants needs splicing for replication. EMBO J 8:359-364.

27. Stamp, J. A., and Wei, A. 2013. The impact of grapevine red blotch virus. Wine Business Monthly, March:56-66.

28. Stanley, J., Bisaro, D. M., Briddon, R. W., Brown, J. K., Fauquet, C. M., Harrison, B. D., Rybicki, E. P., and Stenger, D. C. 2005. Geminiviridae. In: Virus Taxonomy. L. A. Ball, ed. Elsevier/Academic Press, London.

29. Thompson, J., Fuchs, M., Fisher, K., and Perry, K. L. 2012. Macroarray detection of grapevine leafroll associated viruses. J. Virol. Methods 183:161-169.

30. Thompson, J. D., Gibson, T. J., Plewniak, F., Jeanmougin, F., and Higgins, D. G. 1997. The CLUSTAL_X windows interface: Flexible strategies for multiple sequence alignment aided by quality analysis tools. Nucleic Acids Res. 25:4876-4882.

31. Varsani, A., Navas-Castillo, J., Moriones, E., Hernández-Zepeda, C., Idris, A., Brown, J. K., Murilo Zerbini, F., and Martin, D. P. 2014. Establishment of three new genera in the family Geminiviridae: Becurtovirus, Eragrovirus and Turncurtovirus. Arch. Virol. 159:2193-2203.

32. Wilgenbusch, J. C., and Swofford, D. 2003. Inferring evolutionary trees with PAUP*. Curr. Protocol Bioinformatics Chapter 6, Unit 64.

33. Wright, E. A., Heckel, T., Groenendijk, J., Davies, J. W., and Boulton, M. I. 1997. Splicing features in maize streak virus virion- and complementary-sense gene expression. Plant J. 12:1285-1297. 